\title{
DEBATES
}

\section{O buen vivir na América Latina como possibilidade emancipatória nos discursos sobre desenvolvimento}

\author{
The buen vivir in Latin America as an emancipatory possibility in \\ development speeches
}

\section{Isabela Veloso Lopes Versiani Anete Marília Pereira Maria da Luz Alves Ferreira}

\section{Resumo}

Nas últimas décadas, as dificuldades do modelo de desenvolvimento convencional em se tornar, de fato, o grande propulsor de mudanças no campo econômico e, por conseguinte, nas demais esferas da vida social, têm sido criticamente analisadas por teóricos latino-americanos do pós-desenvolvimento e pela busca de alternativas. Com base em pesquisa bibliográfica, o presente artigo tem como objetivo analisar a discussão do buen vivir no campo de estudos sobre o desenvolvimento, procurando entender como essa nova proposta, que incorpora a dimensáo cultural de influência indígena andina na busca por outras formas de ver e se relacionar harmonicamente com o mundo, tem avançado na América Latina. Constata-se que, apesar das dificuldades e desafios, o buen vivir tem ganhado espaço e difusão no plano acadêmico, social e político, abrindo possibilidades para processos de emancipação desses países ante as amarras dos discursos sobre desenvolvimento de base economicista até então dominantes.

\section{Palavras-chave}

América Latina; Desenvolvimento; Buen Vivir.

\begin{abstract}
In the last decades, the difficulties of the conventional development model in becoming, in fact, the great propeller of changes in the economic field and, therefore, in the other spheres of social life, have been critically analyzed by Latin American post-development theorists and the search for alternatives. Based on bibliographical research, this article aims to analyze the discussion on buen vivir in the field of development studies, trying to understand how this new proposal, which incorporates the cultural dimension of indigenous influence from the Andes in the search for other forms of seeing and relating harmoniously to the world, has advanced in Latin America. Despite the difficulties and challenges, buen vivir has gained space and diffusion in the academic, social and political spheres, opening up possibilities to emancipate these countries of the prevailing economic discourse on development.
\end{abstract}

\section{Keywords}

Latin America; Development; Buen Vivir. 


\section{Introdução}

Refletir sobre qualquer tema no âmbito da América Latina pressupóe a busca de convergências em meio a tanta diversidade. Desse modo, pensar a América Latina no contexto atual e a influência de determinantes comuns nos processos históricos, culturais e econômicos de seu desenvolvimento, bem como nas alternativas que têm sido pensadas a partir de novas bases epistemológicas, coloca-se como um grande desafio.

Há múltiplas formas de se buscar entender a América Latina. Para além dos desdobramentos de sua condição de colônia durante séculos, com exploração de suas riquezas naturais e assolamento de suas populaçôes originárias; e da busca por uma suposta modernidade pautada pelo entrelaçamento constante entre o tradicional e o moderno, com tensões e contradições que resultam no fenômeno da hibridação cultural no continente (MARTIN-BARBERO, 2006; CANCLINI, 2008), a prevalência e imposição do paradigma econômico como principal engrenagem de seu processo de desenvolvimento, sobretudo a partir da Segunda Guerra Mundial, é indiscutível.

As consequências negativas dessa configuração têm sido sentidas em todos os países da região, com o agravamento do quadro de desigualdades e pobreza no contexto neoliberal, evidenciando que a história linear trilhada pelo desenvolvimento no Século XX, reduzida em grande medida ao crescimento econômico como um fim em si mesmo, não se traduziu, necessariamente, em ganhos sociais, além dos impactos desastrosos no campo ambiental.

Nos dizeres de Mann (2006), a situação agrava-se por duas "crises situacionais" que marcam praticamente todos os países da região: a infindável dependência dos pagamentos da dívida externa contraída, sobretudo nas décadas de 1960 e 1970, e surpreendida por taxas de juros voláteis praticadas no Ocidente nos anos 1980; e as guerras vinculadas às drogas, tráfico e violência, que reforçam as lutas sociais tradicionais e expóem que o grau de desigualdade entre as classes gera muito dos principais problemas. Este quadro trágico resultante da primazia do econômico frente ao social nos faz refletir. E agora, qual o caminho a seguir? Existem outros modelos de desenvolvimento para a América Latina? É possível pensar alternativas ao desenvolvimento?

O campo de estudos do desenvolvimento é marcado por confrontos teóricos e metodológicos, sobretudo na distinção recente entre crescimento e desenvolvimento, este último entendido como um processo que envolve profundas mudanças 
estruturais, "frequentemente concebido como um processo multidimensional, que não se esgota em seu aspecto econômico" (BERTONCELO, 2011, p. 95).

No quadro atual dos debates, um dos movimentos que problematizam algumas dessas questôes tem sido formulado por teóricos latino-americanos como Arturo Escobar, Gustavo Esteva, Eduardo Gudynas, Alberto Acosta, dentre outros, expoentes de uma visão crítica, construída com base na interpretação do "pósdesenvolvimento" como um campo de emancipação teórico-ideológica nas discussóes e proposiçôes acerca dos modelos de desenvolvimento para a América Latina, sendo o buen vivir uma delas.

Assim, o presente artigo, de natureza exploratória e a partir de pesquisa bibliográfica, tem como objetivo analisar a discussão do buen vivir no campo de estudos sobre o desenvolvimento, buscando entender como essa nova proposta tem se configurado na América Latina, sobretudo como possibilidade de emancipação dessa regiáo para tomar e definir os rumos de seu próprio destino, incorporando o paradigma cultural como essência de sua configuração na busca por outras formas possíveis de ver e se relacionar com o mundo, prevalecendo o bem comum para toda a humanidade.

\section{A imposição de modelos de Desenvolvimento na América Latina}

Apesar das inúmeras divergências que cercam o campo de estudos sobre o desenvolvimento, dentre elas as que se referem à conceituação do fenômeno, à concepção da natureza e dinâmica do desenvolvimento, aos métodos de investigação e às estratégias para intervenção - relacionadas ao papel do Estado ou da sociedade civil (BERTONCELO, 2011), as diferentes reflexões produzidas são importantes para se construir e/ou desconstruir mitos e alternativas sobre o desenvolvimento em cada contexto em análise.

No caso da América Latina, esta irá se constituir como um campo próprio de análise e aplicação de diversos modelos de desenvolvimento para sua "modernização", objeto de manejo para teorias e experiências diversas que em comum travaram com suas principais críticas à oposição entre a submissão aos imperativos do mainstream econômico das grandes potências e a busca de autonomia nos desígnios de seu destino, especialmente na conjuntura referente ao papel do Estado, correlação de forças sociais internas e inserção no cenário econômico mundial de cada país. 
É consenso estabelecer como recorte temporal para o aparecimento da noção de desenvolvimento, tanto na economia como na política, bem como na formaçáo de um campo de estudos mais específico, o contexto do Pós-Segunda Guerra, resultado de um conjunto de mudanças geopolíticas e econômicas importantes, como os processos de descolonização nos continentes africano e asiático, o início da Guerra Fria e mudanças no sistema econômico mundial em decorrência da Grande Depressão e expansão do capitalismo monopolista (GAITÁN, 2001; BERTONCELO, 2011; IVO, 2012).

Nesse cenário, a problemática fundamental buscava explicar as diferenças entre as experiências de desenvolvimento dos países industrializados e daqueles que se desligavam dos laços coloniais, ou dos que já haviam se desligado - como no caso de alguns países latino-americanos - e as transformaçóes por que passavam, resultantes de mudanças na vinculação destes à economia mundial, sobretudo com influência da teoria da modernização (BERTONCELO, 2011). Essa teoria baseia-se na ideia de que os processos de modernizaçáo econômicos são capazes de produzir as mudanças sociais. Sob essa ótica, as sociedades tradicionais poderiam se tornar desenvolvidas dependendo, para isso, do padrão de investimento realizado'.

Assim, desenvolvimento implicava a modernizaçáo de um conjunto de condiçóes econômicas, sociais, institucionais e ideológicas de um país, o que corresponderia à geração de condiçôes para se adotar padrōes vigentes nos países capitalistas centrais, podendo ser reproduzidos, nos países do "Terceiro Mundo", os mesmos efeitos sociais conquistados desde que certas medidas fossem adotadas (GAITÁN, 2001). Este se daria por meio de uma teoria evolucionista, linear e de um processo homogeneizador, fundamentado na oposição entre formas "tradicionais" e "modernas" de organização da vida social, que resultariam em mudanças em diversas dimensões como na industrialização, urbanização, elevação da mobilidade social, diferenciação estrutural e secularização (BERTONCELO, 2011, p. 97), sintetizado na busca do crescimento sustentado do produto per capita com base na industrialização, progresso técnico e modernização das relações produtivas (IVO, 2012).

O debate que se segue nas décadas de 1950 e 1970, principalmente na América Latina, busca equalizar as críticas feitas à teoria da modernização e seu viés etnocêntrico, evolucionista e funcionalista acerca da incompatibilidade entre o

\footnotetext{
${ }^{1}$ A teoria da modernização teve em W. W. Rostow (1959) um dos seus principais expoentes. No Brasil, Roberto Campos (1963) tornou-se um dos teóricos mais influentes.
} 
"tradicional" e o "moderno" - que desconsiderava caminhos alternativos ao desenvolvimento - desdobrando-se nas perspectivas estruturalistas da Comissão para Estudos da América Latina e Caribe (CEPAL) e da teoria da dependência, que criticavam essa oposição entre tradicional e moderno como elemento analítico central para explicar o desenvolvimento, sendo que, para ambas, o desenvolvimento seria moldado "historicamente pela forma de vinculação das sociedades nacionais ao sistema econômico mundial, hierarquicamente organizado. E tais formas de vinculação moldam a estrutura social interna (assim como esta condiciona as formas de vinculação à economia internacional)" (BERTONCELO, 2011, p. 98).

Dessa forma, permanecer na periferia do sistema capitalista é uma condição estrutural, historicamente moldada, resultado da expansão do sistema capitalista global, em que a categoria subdesenvolvimento vai substituir a noção de atraso ou de uma mera etapa a ser superada por meio do processo de modernização, sendo que, para a CEPAL, a possibilidade de desenvolvimento na periferia seria possível mediante mudanças profundas na forma de vinculação das economias desses países ao sistema capitalista mundial via industrialização, com forte intervenção do Estado para conduzir o processo por meio de um desenvolvimento autossustentado, enquanto a teoria da dependência destacava os limites estruturais severos no plano interno e externo, o que reduzia a margem de manobra da ação estatal, seguindo duas vertentes: a de que a dependência externa bloqueava o desenvolvimento da "periferia", sendo necessária a desvinculação do sistema capitalista mundial como única forma de superação do subdesenvolvimento; e outra que entendia que a natureza e dinamismo do desenvolvimento na "periferia" seriam resultado das configurações formadas pelas relaçôes das alianças sociopolíticas expressas no nível do Estado, no âmbito interno, com as relaçôes entre os centros de poder econômico e político mundial, no externo (BERTONCELO, 2011)2.

\footnotetext{
${ }^{2} \mathrm{O}$ marco inicial do estruturalismo como perspectiva de análise do desenvolvimento está diretamente ligado à diversas produçóes da CEPAL, tendo, como marco inicial, o artigo do economista argentino Raúl Prebisch, $O$ desenvolvimento na América Latina e alguns de seus problemas principais, publicado em 1949, e outras contribuiçóes, dentre elas as do economista e pensador brasileiro Celso Furtado, a exemplo da obra Desenvolvimento e Subdesenvolvimento, de 1961. Na teoria da dependência, destacam-se, na primeira vertente, autores como Andre Gunder Frank e a obra El desarrollo del subdesarrollo, de 1967; Theotonio dos Santos e a obra The structure of dependence, de 1970; e Ruy Marini com a obra Dialéctica de la dependência, de 1977. Na segunda vertente, destacam-se Fernando Henrique Cardoso e Enzo Faletto, tendo como obra clássica Dependência e desenvolvimento na América Latina, de 1970.
} 
Apesar das críticas, os resultados desses embates no plano teórico não vieram de fato a se consolidar efetivamente na realidade, por diversas razóes que aqui não serão exploradas, mas abriram margem para a reflexão de que a modernização conservadora que se fez possível, especialmente no caso do Brasil, se restringiu "ao progresso técnico e ao crescimento econômico altamente concentrador, sem mudança significativa da distribuição da renda e das relações políticas e sociais assentadas numa cultura política patrimonial e autoritária"; e, em um contexto no qual a questáo social se caracteriza por extrema pobreza, altos índices de desigualdades sociais e um Estado de Bem-Estar incompleto, teve como herança a ampliação de desigualdades socioeconômicas e culturais (IVO, 2012, p. 196). Complementando esta análise, a mesma autora destaca que:

O debate sociológico do modelo de desenvolvimento diz respeito ao tema da distribuição, ou da justiça distributiva, o que implica pensar como os resultados da economia são apropriados socialmente, questionando 'como' se está crescendo e 'para quem' se dirigem os resultados dessas políticas e os custos desse crescimento, do ponto de vista da qualidade e bem-estar dos cidadãos. Portanto, a modernização conservadora e excludente contém dimensóes sociais, políticas e institucionais legitimadoras do regime de concentração de riqueza, o que, no caso brasileiro, produziu uma massa de excluídos e padróes de desigualdade de renda extremamente elevados entre trabalhadores, grupos e (ou) regióes (IVO, 2012, p. 195).

Se nesse processo de desenvolvimento na América Latina, em que se tinham orientaçóes claras para a necessidade de mudanças profundas em diferentes aspectos da vida social, apenas açôes pontuais e restritas à geração de crescimento econômico com base na ideia de "progresso" foram implementadas, sem, contudo, conseguir atingir graus de desenvolvimento semelhantes aos moldes usufruídos pelos países centrais em todas as dimensôes - com o agravante ainda de Golpes Militares e governos ditatoriais no mesmo período em muitos países da região -, o cenário que se seguiu nos anos 1980 mostrou-se menos promissor ainda.

Embora avanços sejam reconhecidos a partir do processo de redemocratização das instituiçôes jurídicas e políticas de muitos desses países, como no Brasil, as inflexôes dos anos 1980 no plano internacional - com o diagnóstico conservador da governabilidade que fundamentou a ruptura com o pacto distributivo do Estado de bem-estar em curso, em função da tese do déficit fiscal em muitos países centrais tiveram efeitos sociais, nos anos 1990, ainda mais graves nas sociedades latino- 
americanas, devido ao caráter ainda incompleto dos regimes de bem-estar social nesses países (IVO, 2012).

Como consequência dessas inflexôes, a primazia do pensamento neoliberal foi imposta para a América Latina, fundamentada no discurso da ausência de caminhos alternativos para superar a crise que evidenciava na região "a queda do crescimento, a inflação, a erosão dos sistemas fiscais e da balança de pagamentos, a baixa competitividade e capacidade de adaptação dos sistemas produtivos às crescentes exigências da economia mundial" (GAITÁN, 2001, p. 59), com reflexos diretos no papel e funçáo a serem desempenhados pelos Estados, claramente estabelecidos pelo Consenso de Washington, em 1989, e pelo conjunto de recomendações de ajuste econômico e reformas estruturais que se seguiram para os países de "Terceiro Mundo”, especialmente da América Latina.

Essa transição alterou as responsabilidades do Estado nacional como promotor e regulador do desenvolvimento, observando-se uma desconcentração do poder do Estado nacional, reorientado por reformas em favor do mercado, através das privatizaçóes, e operando a descentralização de políticas sociais com ênfase nas dinâmicas locais, na passagem de responsabilidades públicas para a esfera da sociedade civil, com base no modelo de "parcerias público e privado", e, em termos de Seguridade e proteção, reorientando o princípio do Estado (social) protetor de caráter universalista para um Estado de assistência focalizada sobre os mais pobres, etc. (IVO, 2012, p. 198).

Para Bertoncelo (2011, p. 113), “as transformações no capitalismo mundial a partir do final da década de 1970 modificaram drasticamente as possibilidades de construção de estratégias nacionais de desenvolvimento", com progressiva desregulamentação dos governos nacionais para definir políticas econômicas, com sobreposição das cadeias globais de mercadorias e atençáo às posiçóes nelas ocupadas pelas economias nacionais a partir de sistemas integrados de produção, desenvolvimento e distribuição de produtos e serviços em escala transnacional, além da transformação do sistema financeiro internacional e dos fluxos de crédito concedidos pelas agências multilaterais (como o Fundo Monetário Internacional FMI e o Banco Mundial) cada vez mais vinculados a reformas liberalizantes, especialmente para os países da América Latina.

Diante dessa conjuntura de internacionalização que se impõe aos Estados latino-americanos, é possível ainda vislumbrar estratégias nacionais de 
desenvolvimento? Para o mesmo autor, é preciso atentar "para o fato de que a definição de certos objetivos associados a uma concepção de desenvolvimento afeta não apenas a escolha da perspectiva teórica e a organização de evidências empíricas, como também influencia a formulação de estratégias" (BERTONCELO, 2011, p. 116). Nessa perspectiva:

o desenvolvimento é um processo multidimensional e multifacetado que supóe relaçóes complexas entre o Estado, a economia e a sociedade. O desafio está em investigar os arranjos institucionais e estruturais que sustentam tais relaçóes (tanto no plano interno quanto externo) e que determinam graus variados de autonomia e de capacidade dos Estados nacionais para imprimir um padrão específico ao processo de desenvolvimento (BERTONCELO, 2011, p. 116).

Ainda para o mesmo autor, corroborando com o pensamento de muitos autores da teoria da dependência, "os tipos de intervençáo do Estado na economia e na vida social mais ampla e os instrumentos que utiliza nessa empreitada são determinados pelos arranjos institucionais existentes, dentro de limites estruturais associados" que, no plano interno, estão diretamente ligados às relaçôes de poder entre as classes e grupos sociais e, no plano externo, dependem das formas de inserção das economias e sociedades nacionais no sistema mundial e das normas que regulam o comércio e investimentos entre os países (BERTONCELO, 2011, p. 116).

Segundo Diniz (2001), um dos maiores desafios para o risco da governabilidade é justamente o equilíbrio entre o ajuste interno e a inserção internacional, uma vez que as fortes assimetrias no sistema de poder internacional tornam bastante improvável para qualquer Estado, agindo isoladamente, alterar a seu favor o equilíbrio de forças, sendo necessária a definição de estratégias nacionais concertadas, tendo em vista a reversão de situaçôes desfavoráveis, particularmente no que tange aos países em desenvolvimento, uma vez que "não se deve esquecer que estes se encontram subordinados a instituições de governança dominadas pelos países mais desenvolvidos, ciosos de preservar suas condições de hegemonia" (DINIZ, 2001, p. 34).

O Consenso de Washington instaurou uma nova agenda pública, com uniformização de agendas nacionais, implicando em um conjunto de prioridades necessárias para se recuperar a rota de desenvolvimento prevista no receituário do mercado, a saber: "estabilização econômica, disciplina fiscal, controle do gasto público, com redução do escopo dos programas sociais, liberalização comercial e 
financeira, crescente abertura da economia (comercial e financeira), privatização das empresas estatais e regulamentaçáo", que tiveram como consequência radical no plano político “a primazia da idéia da ineficiência do Estado, crescentemente percebido como fonte de irracionalidades, desperdício, corrupção e distorções de toda ordem" (DINIZ, 2001, p. 35-36).

Porém, o Pós-Consenso de Washington instaura uma conjuntura crítica nos primeiros anos do terceiro milênio, que tem produzido reflexôes importantes sobre uma reinterpretação do processo de globalização e aberto um questionamento da ortodoxia sustentada pelos organismos multilaterais, como o FMI e o Banco Mundial, cujas prescrições, ao invés de estimularem o desenvolvimento, na verdade, contribuíram para a sua asfixia (DINIZ, 2001). Para a mesma autora:

\begin{abstract}
Nesse contexto, sobressai o pensamento crítico e abre-se espaço para novas reflexôes e novas formulaçôes. Torna-se possível vislumbrar a perspectiva de mudança sem ruptura, respeitando-se as regras do jogo político. Tal perspectiva baseia-se no reconhecimento de que na ordem globalizada contemporânea existem, sim, graus de liberdade de ação em benefício de interesses nacionais estratégicos. Os Estados podem atuar com autonomia, utilizando de forma consistente suas vantagens materiais e institucionais comparativas. Governos independentes, com base na legitimidade conferida por coalizóes de sustentação política identificadas com uma agenda alternativa que contemple as novas prioridades nascidas da interlocução entre os principais atores sociais, podem ter êxito na conquista de um novo patamar e de maior poder de barganha na ordem internacional (DINIZ, 2001, p. 37).
\end{abstract}

Na base das críticas formuladas por esse novo debate, Diniz (2001) destaca cinco aspectos a serem considerados, que vão desde o questionamento da existência de um receituário único à rejeição do pressuposto $\mathrm{da}$ convergência $\mathrm{e} \mathrm{da}$ uniformização, bem como da ideia correlata de importar modelos sem levar em conta as especificidades da trajetória de cada país, passando pela crítica da negação do Estado e da recusa da postura passiva até a crítica da ideia de que existe um só caminho apropriado à realidade internacional.

Novas concepções sobre o que seja desenvolvimento têm refletido sobre a constatação de que mudanças estruturais no sistema econômico com o objetivo de potencializar o crescimento não necessariamente estendem os atributos conquistados para demais áreas e para a sociedade de maneira equitativa, com o agravante ainda, 
cada vez mais denunciado nos debates políticos e da sociedade civil mundo afora, das consequências desastrosas desse viés econômico sobre o meio ambiente e a sustentabilidade, não só do capitalismo, mas da própria humanidade.

Perante essa conjuntura, torna-se fundamental repensar o papel da dimensão política e do Estado. Para Diniz (2001), é preciso resgatar a nova visão das funçôes do Estado tanto na ordem econômica, como no campo das políticas sociais e ambientais, sendo necessária a superação de dicotomias como: Estado versus mercado ou de desenvolvimento versus sustentabilidade.

À antiga concepção economicista do desenvolvimento, contrapóe-se a visão mais complexa que enfatiza seu teor multidimensional, com destaque para as dimensões ética, da equidade e sustentabilidade. Tais dimensóes deixam de ser percebidas como prioridades isoladas e passam a ser consideradas aspectos indissociáveis da concepção atual de desenvolvimento. E para sua consecução impóe-se a transversalidade das políticas públicas, bem como o alto grau de capacidade de coordenação do Estado, condição para torná-las exequíveis (DINIZ, 2001, p. 51).

No que se refere ao papel do Estado, Mann (2006, p. 191) destaca que o sucesso em termos de poderes infraestruturais (ligados à capacidade do Estado de efetivamente implementar decisóes em todo o seu território que penetrem universalmente a sociedade civil e desenvolvam um senso comum de cidadania nacional) só é passível de ser alcançado por Estados com sociedades relativamente homogêneas e igualitárias; ressalta também que "promover isso - através de reformas econômica, política, militar e cultural - deve ser a principal tarefa do século XXI em toda a América Latina. Sem isso, não apenas o mero desenvolvimento econômico, mas também o tecido social é colocado em risco".

Chega-se, então, à constatação da não sustentabilidade desse modelo de desenvolvimento pautado no crescimento econômico como um fim em si mesmo, seja direcionado pelo Estado seja pelo Mercado, principalmente na direção de reduzir as desigualdades marcantes existentes na América Latina. Daí a necessidade urgente de se pensar alternativas a esse desenvolvimento convencional que até então se impôs à América Latina de forma autoritária, periférica e excludente. 


\section{O buen vivir como alternativa emancipatória da América Latina}

A discussão realizada até aqui retrata a denúncia mais recente, feita por teóricos do pós- desenvolvimento, da crítica radical ao atual estado das relações de poder, dominação e exploração na América Latina, na qual expõem que as promessas de bem-estar do desenvolvimento convencional não passaram de simples ilusões, resultando em um balanço negativo de sua aplicação e de suas bases conceituais, expressões práticas, instituições e formas de legitimação (GUDYNAS, 2014).

A partir de uma perspectiva que busca desconstruir os modos de pensar e agir em nome do desenvolvimento, Arturo Escobar (1995), que é um dos principais expoentes desse movimento, define que essa abordagem tem um grande potencial ao pôr em evidência a dimensão apenas técnica do desenvolvimento, baseada em uma pretensa objetividade científica, mas que também o considera como um fenômeno cultural, denunciando a supressão de culturas locais e das resistências que destas emergem pelo modelo convencional e etnocêntrico, que contribuiu para determinar a representação e identidade de países do Sul como subdesenvolvidos, atrasados, dentre outras associações.

Assim, o pós-desenvolvimento sintetiza um movimento de desconstrução do discurso sobre o desenvolvimento e da própria modernidade em diferentes aspectos. Embora não seja sua função específica propor modelos alternativos concretos - e essa é uma das principais críticas, dentre outras como a de ser um modelo simplista, romântico ou populista, a que se dirigem algumas correntes, especialmente do Norte (GUDYNAS, 2014) - é inegável que sua influência como uma teoria crítica de análise do desenvolvimento e de seus desdobramentos contribuiu de forma significativa para se pensar, influenciar e reafirmar a necessidade de outros modelos.

Em meio à existência de "desenvolvimentos alternativos" que, apesar de representarem uma crítica às visões mais ortodoxas do desenvolvimento, possuem uma limitada capacidade de mudança - principalmente porque os elementos medulares do desenvolvimento se organizam para incorporar os questionamentos, como nos casos conhecidos do Desenvolvimento Humano (PNUD) ou das críticas ambientais mais recentes, que associam às novas modalidades de desenvolvimento sustentáveis uma reinterpretação da própria conservação econômica -, destaca-se o aparecimento de análises mais críticas colocadas como "alternativas ao desenvolvimento", que buscam opções de mudanças que estão além das bases conceituais tradicionais, fundamentadas, sobretudo, no questionamento da 
linearidade da história, renúncia à fé no progresso, imposição cultural ocidental e separaçáo entre sociedade e natureza, sendo a proposta do buen vivir uma dessas alternativas (GUDYNAS, 2014 p. 79).

Para Alberto Acosta, economista equatoriano e um dos maiores expoentes do buen vivir, assim como Eduardo Gudynas, a América Latina e toda a humanidade encontram-se em uma encruzilhada, na qual os limites e estilos de vida sustentados pela visão do desenvolvimento associado ao progresso clássico são cada vez mais notáveis e preocupantes, e os recursos naturais não podem mais ser assumidos como uma condiçáo para o crescimento econômico ou simples objeto das políticas de desenvolvimento, como o caso recente do neoextrativismo presente em governos progressistas "de esquerda" em vários países da região, sendo que "la promesa hecha hace mas de cinco siglos, en nombre del 'progreso', y 'reciclada' hace mas de seis decadas, en nombre del 'desarrollo', no se ha cumplido. $Y$ no se cumplira” (ACOSTA, 2014, p. 31).

Embora a região da América Latina tenha tido um papel importante na geração de revisôes que contestaram em certa medida o desenvolvimento convencional, como foram o estruturalismo ou as diferentes ênfases na teoria da dependência, até chegar a outras posiçôes mais recentes, essas propostas, no entanto, não prosperaram, principalmente pelas limitaçóes de não questionarem seriamente os núcleos conceituais da ideia de desenvolvimento convencional entendida a partir de progressos lineares e, em especial, expressa em termos de crescimento econômico, resultando em processos de redefinição das características do desenvolvimento e suas consequentes adjetivações em maior ou menor evidência, ora como econômico, ora como social, humano, ecológico, sustentável, rural, local, regional, entre outros, sem, contudo, questionar a crença no modelo de desenvolvimento padrão, o que ocasionou sempre na retomada da posição convencional como protagonista (ACOSTA, 2014). Para o mesmo autor: 
La dificultad radica en el concepto. El desarrollo, em tanto propuesta global y unificadora desconoce de una manera violenta los sueńos y luchas de los pueblos 'subdesarrollados'. Esta negacion violenta de lo propio fue muchas veces producto de la accion directa o indirecta de las naciones consideradas como desarrolladas. Ademas, ahora sabemos que el desarrollo, en tanto redicion de los estilos de vida de los paises centrales, resulta irrepetible a nivel global. Dicho estilo de vida consumista y depredador, ademas, esta poniendo en riesgo el equilibrio ecologico global, y margina cada vez mas masas de seres humanos de las (supuestas) ventajas del ansiado desarrollo (ACOSTA, 2014, p. 25).

Dessas constatações emergem críticas e buscas por construçôes alternativas ao modelo civilizatório ocidental e moderno (capitalista, competitivo, individualista, consumista e devastador da natureza e da humanidade) que tenta se impor às demais partes do mundo, e que tem no "discurso", antes, do progresso e, mais recentemente, do desenvolvimento, feito pelos países hegemônicos e organismos internacionais, o respaldo e a pretensa legitimidade para disseminar ideias, conceitos, estratégias e práticas, sempre aliado ao crescimento econômico como solução mágica para todos os problemas da humanidade.

Nesse cenário, tem ganhado legitimidade o resgate e a necessidade de outros modelos civilizatórios existentes e possíveis, baseados em reflexóes sobre povos e comunidades que conseguem viver em harmonia não só com o outro, mas com o seu entorno e a natureza, a partir de outras lógicas de vida e princípios éticos que diferem do que até então se tenta reafirmar como único modelo civilizatório possível e desejado nos moldes ocidental e capitalista. Aportes advindos dos povos indígenas e de outras comunidades tradicionais têm ganhado relevância no debate acadêmico e político, no qual se destaca o protagonismo da visão do buen vivir.

O buen vivir, enquanto proposta, congrega um esforço de produzir um diálogo epistêmico que se desdobra em um horizonte imaginativo e criativo para, no exercício da crítica e da controvérsia, pensar as contradiçôes e o poder da experiência social de acordo com a produção nos lugares particulares dos movimentos e dos sujeitos sociais, dando um peso fundamental à especificidade cultural dos grandes grupos sociais periféricos, com reflexôes relevantes no sul da Amazônia e região Andina, mas também presentes no restante do continente latino-americano (ACOSTA, 2014).

Desse modo, uma das vertentes do buen vivir destaca como centralidade a utopia de povos indígenas, sobretudo de países andinos, seus conhecimentos, 
sensibilidades e práticas sobre o que se considera uma "boa vida", sendo sintetizada nas expressóes mais difundidas de sumak kawsa dos kichwas do Equador, e suma qamaña dos aymara da Bolívia, mas também encontrada com sentidos similares nas noçôes de ñande reko dos guaranis, shiir waras dos ashuar da Amazônia Equatoriana, ou kume morgen para os mapuches do sul do Chile, que não incluem ideias análogas a desenvolvimento ou progresso, nem estão restritas ao consumo material (GUDYNAS, 2014).

Ao retratar a essência da filosofia indígena que busca uma vida em harmonia com os seres humanos e com a natureza, vivendo em comunidades, que não foram totalmente absorvidas pela modernidade capitalista ou que resolveram ficar de fora dela, mesmo com os processos de exploração e repressão colonial, o buen vivir representa uma abordagem holística, com diversos elementos e açóes que se integram a partir de conhecimentos e códigos de conduta ética e espiritual na relação com o meio ambiente, valores humanos, visão do futuro, entre outros, afirmando-se como um conjunto de práticas de resistência ao colonialismo e suas sequelas, na qual o desenvolvimento convencional é visto como uma imposição cultural e colonial, herdeira do conhecimento ocidental, sendo uma de suas tarefas a de contribuir para um processo de descolonização intelectual para descolonizar a economia, a política e a sociedade (ACOSTA, 2014).

A partir da crítica à lógica antropocêntrica do capitalismo como projeto civilizatório dominante, como também dos socialismos realmente existentes até então, que deverão repensar-se, o buen vivir parte de posturas sociobiocêntricas para propor uma reconstrução dos estilos de vida desde a visão utópica de futuro andina e amazônica, que deve complementar-se e ampliar-se incorporando outros discursos e propostas provenientes de diversas regiôes do planeta que também buscam uma transformação civilizatória, com diferentes visões humanistas e anti-utilitaristas, o que resulta em visões de vida heterogêneas e plurais, sendo mais adequado falar em buenos convivires a serem buscados (ACOSTA, 2014).

Dessa forma, o buen vivir constitui-se em um caminho que deve ser imaginado para ser construído, que não se configura como uma proposta totalmente elaborada ou indiscutível, mas que se apresenta como uma oportunidade de construir coletivamente novos estilos de vida, não como um livro de receitas, mas que integra uma longa busca de alternativas que emergem no calor das lutas populares, particularmente dos povos e nacionalidades tradicionalmente marginalizadas, com propostas que convidam a questionar a raiz de vários conceitos assumidos como indiscutíveis (ACOSTA, 2014). 
Apesar da pluralidade de entendimentos e sensibilidades que envolvem o buen vivir, Gudynas (2014) ressalta que é mais apropriado concebê-lo, então, como uma plataforma compartilhada de crítica ao desenvolvimento convencional e seus fundamentos modernos, reconhecido como um espaço plural, que se configura tanto pela diversidade de saberes quanto pela interculturalidade, valorização dos povos indígenas e de outras formas de ver o mundo.

Pode-se reconhecer que o que assegura o buen vivir como alternativa ao desenvolvimento é justamente a manutenção de seus ideais e atributos de ruptura com características do desenvolvimento tradicional e da linearidade dos processos, incorporando a diversidade cultural como essência de sua configuração, e disseminando pressupostos teóricos que são universais, mas não impositivos, buscando o necessário equilíbrio entre um enfoque regional ou local adequado a cada especificidade, porém sem uma fragmentação excessiva que comprometa a sua potencial universalidade na direção do bem comum para a humanidade.

Ao realizar uma crítica da história linear e de que o desenvolvimento se faz a partir de critérios pré-estabelecidos, independentemente do ponto de chegada, mas em uma determinada direção, tem-se o princípio da não-linearidade como motriz desse processo, no qual os modelos de desenvolvimento são desconstruídos e reconstruídos a partir de identidades do que é a "boa vida" coletivamente construída, com contribuições de distintos saberes indígenas, mas também de outros, fundamentais para sua composição no sentido de formar seus conceitos e sensibilidades (GUDYNAS, 2014).

Seria muita ingenuidade pensar que modelos alternativos ao desenvolvimento serão pensados a partir do mainstream econômico hegemônico. Isso não vai acontecer. Nesse ponto, destaca-se a contribuição desse novo paradigma como possibilidade emancipatória da América Latina na condução de seu próprio destino e dos múltiplos caminhos que se abrem a partir da busca de uma nova ética e sentido para direcionar os rumos não só de suas economias, mas fundamentalmente de suas sociedades e da relação com a natureza. Como destacado por Acosta (2014, p. 39), "lo que realmente interesa es que se trata de una propuesta que surge desde la periferia, desde los historicamente marginados", eminentemente subversiva, que propõe saídas descolonizadoras e se coloca como alternativa ao desenvolvimento e como proposta civilizatória que reconfigura um horizonte de saída ao capitalismo. 
Desde esa perspectiva, el Buen Vivir se transforma en el punto de partida, camino y horizonte para deconstruir la matriz colonial que desconoce la diversidad cultural, ecologica y politica. En esta linea de reflexion, la propuesta del Buen Vivir critica al Estado monocultural, al deterioro de la calidad de vida materializado en las crisis econômicas y ambientales, a la economia capitalista de mercado, a la perdida de la soberania en todos los ambitos, la marginalizacion, la discriminacion, la pobreza, las deplorables condiciones de vida de la mayoria de la poblacion, las inequidades. Igualmente, cuestiona aquellas visiones ideologicas que se nutren de las matrices coloniales del extractivismo y la misma evangelizacion impuesta a sangre y fuego (ACOSTA, 2014, p. 44).

Não só se fundamenta a partir de uma ética comunitária em todas as direções, para não colocar em risco a vida das próximas gerações, mas também implica distribuir e redistribuir agora a renda, para começar a estabelecer as bases de uma sociedade mais justa e equitativa, isto é, mais livre e igual, na qual emerja a necessidade de uma nova economia, com mudanças profundas na organização do aparato produtivo e nos padróes de consumo, que se reencontre com a Natureza e atenda às demandas da sociedade e não do capital (ACOSTA, 2014).

É claro que esse caminho não será fácil e envolve um conjunto de dificuldades e fragilidades. Uma das maiores ameaças evidenciadas por Acosta (2014) está no uso simplista e carente de significado mais aprofundado que, por vezes, é atribuído ao termo buen vivir, restrito ao campo teórico ou à dimensão utópica particularista; ou nas incongruências que aparecem em governos progressistas, os quais, tanto em nível nacional como em territórios descentralizados, apesar das intenções previstas nas Constituições e documentos oficiais relacionados ao termo, como no caso do Equador e da Bolívia, continuam a fomentar práticas de consumismo e produtivismo, neodesenvolvimentistas e neoextrativistas, apegadas à mesma lógica de acumulação capitalista, reduzindo o buen vivir apenas a uma ferramenta propagandística e produto de marketing publicitário para determinada política oficial.

Apesar das dificuldades e desafios, o buen vivir, como um conjunto de ideais que partiram dos países andinos, tem ganhado espaço e difusão, inclusive com afirmações e conquistas no plano acadêmico, social e político. Entendido como um campo plural, no qual os movimentos que compartilham seus ideais não são idênticos entre si, valorizando-se os devidos ajustes que devem ser feitos a cada história, contexto cultural e marco ecológico (GUDYNAS, 2014), exalta a importância da diversidade na construção de outros caminhos possíveis, baseada na pluralidade de 
alternativas e de seu enorme potencial, podendo se constituir de fato como uma importante ferramenta de emancipação para toda a América Latina, que começa a ganhar contornos mais efetivos a partir de sua incorporação, em 2008 e 2009, como paradigma socioeconômico nas Constituiçôes do Equador e da Bolívia para construção de outro projeto de sociedade possível.

\section{Considerações finais}

A constatação das falhas e dificuldades do modelo de desenvolvimento convencional em se tornar, de fato, o grande propulsor de mudanças significativas no campo econômico e, por consequência, nas demais esferas da vida social, aqui evidenciadas, reforça a crítica a que esse paradigma tem sido exaustivamente submetido, principalmente por novas epistemologias do Sul, que denunciam seu caráter colonial, etnocêntrico, linear, hegemônico e excludente.

Os resultados da aplicação desse modelo na América Latina, amparado na teoria da modernização conservadora ou, mais recentemente, pela ótica neoliberal, não trouxeram o tão sonhado e desejado "desenvolvimento" em diferentes sentidos e para a imensa maioria das populações desses países, que continuam marginalizadas e alijadas desse processo, vítimas de novas modalidades de relaçôes produtivas semelhantes à exploração dos moldes coloniais, como o caso do neoextrativismo cada vez mais presente, que exacerba violências contra a própria sociedade e, sobretudo, contra a Natureza.

Essa conjuntura continua a impedir a América Latina de definir e seguir os rumos de seu destino e, principalmente, de conseguir reduzir desigualdades, tanto no plano interno e das assimetrias sociais na distribuição da riqueza quanto no acesso a direitos que comprometem seu "tecido social" e sua inserção mais autônoma no plano externo com relação às questôes econômicas e debates políticos.

É desse contexto que o buen vivir emerge como um importante paradigma que contesta o modelo de desenvolvimento convencional e configura várias possibilidades que se abrem, refletindo no plano teórico e, sobretudo, político, a necessidade de complexificar as interaçôes e inter-relações entre as esferas econômica, social, ambiental e, sobretudo cultural, no sentido de ser por meio desta que se instaura uma nova ética para o desenvolvimento incrustada no tecido social e na relação harmônica com a Natureza, ou melhor, amplia-se o campo de "alternativas ao desenvolvimento”, conforme evidenciado por Gudynas (2014, p. 79). 
É difícil dizer se, de fato, o buen vivir será capaz de se consolidar como uma alternativa para superar o sistema capitalista e sua essência desigual, depredatória e exploradora. Isso só o futuro dirá. Com a esperança da utopia em formação no debate político mais recente de alguns países da América Latina, finaliza-se por ora esse debate na expectativa de que o Brasil também desperte para as potencialidades do buen vivir difundida por nossos vizinhos.

- Isabela Veloso Lopes Versiani é Doutoranda do Programa de Pós-Graduação em Desenvolvimento Social - PPGDS, da Universidade Estadual de Montes Claros - UNIMONTES. Vinculada ao Departamento de Educação Física e Desporto da mesma instituição. Mestre em Desenvolvimento Social - PPGDS. Graduada em Educação Física e Ciências Sociais. E-mail: isabelamoc@yahoo.com.br.

Anete Marília Pereira é Professora do Programa de PósGraduação em Desenvolvimento Social - PPGDS, da Universidade Estadual de Montes Claros - UNIMONTES. Vinculada ao Departamento de Geografia da mesma instituição. Doutora em Geografia pela Universidade Federal de Uberlândia e Mestre em Geografia Humana pela Universidade Federal de Minas Gerais. Email: anete.pereira@unimontes.br.

Maria da Luz Alves Ferreira é Professora do Programa de PósGraduação em Desenvolvimento Social - PPGDS, da Universidade Estadual de Montes Claros - UNIMONTES. Vinculada ao Departamento de Ciências Sociais da mesma instituição. Doutora em Sociologia e Politica pela Universidade Federal de Minas Gerais e Mestre em Sociologia pela Universidade de Brasília. E-mail: mariadaluz@oi.com.br. 


\section{Referências}

ACOSTA, Alberto. El Buen Vivir, mas alla del desarrollo. In: RAMOS, G. C. D. (Org.) Buena vida, buen vivir: imaginarios alternativos para el bien común de la humanidad. México: UNAM, 2014, p. 21-60. Disponível em: <http://209.177.156.169/libreria_cm/archivos/pdf_1508.pdf>. Acesso em: 03 set. 2018.

BERTONCELO, Edison. Revisitando os estudos de Desenvolvimento. Revista Brasileira de Informação Bibliográfica em Ciências Sociais - BIB, São Paulo, n. 71, p. 95-122, 2011.

CAMPOS, Roberto de Oliveira. Economia, planejamento e nacionalismo. Rio de Janeiro: Apec, 1963.

CANCLINI, Néstor. Culturas Híbridas: estratégias para entrar e sair da modernidade. São Paulo: Edusp, 2008.

CARDOSO, Fernando; FALETO, Enzo. Dependência e desenvolvimento na América Latina. $7^{\text {a }}$ Ed. Rio de Janeiro: LTC, 1970.

DINIZ, Eli. Depois do Neoliberalismo: redistribuindo a articulação Estado e desenvolvimento no novo milênio. In: BOSCHI, R. (Org.). Variedades de Capitalismo e Desenvolvimento na América Latina. Belo Horizonte: Editora da UFMG, 2001, p. 31-55.

ESCOBAR, Arturo. Encountering development. The making and unmaking of the Third World. Princeton: Princeton University Press, 1995.

ESTEVA, Gustavo. Desenvolvimento. In: SACHS, W. (Org.). Dicionário do Desenvolvimento: guia para o conhecimento como poder. Petrópolis: Editora Vozes, 2000, p. 59-83.

FRANK, Andre. El desarrollo del subdesarrollo. Pensamiento Crítico, La Habana. Cuba, v. 1, n. 7, p. 159-172, 1967.

FURTADO, Celso. Desenvolvimento e Subdesenvolvimento. Rio de Janeiro: Fundo de Cultura, 1961.

GAITÁN, Flavio. Desenvolvimento Esquivo e as Tensões do Desenvolvimentismo: Reflexóes sobre a América Latina na hora atual. In: BOSCHI, R. (Org.). Variedades de Capitalismo e Desenvolvimento na América Latina. Belo Horizonte: Editora da UFMG, 2001, p. 56-85.

GUDYNAS, Eduardo. El postdesarrollo como critica y el Buen Vivir como alternativa. In: RAMOS, G. C. D. (Org.). Buena vida, buen vivir: imaginarios alternativos para el bien común de la humanidad. México: UNAM, p. 61-96, 2014. Disponível em: <http://209.177.156.169/libreria_cm/archivos/pdf_1508.pdf. Acesso em: 03 set. 2018.

IVO, Anete. O Paradigma do Desenvolvimento: do mito fundador ao novo desenvolvimento. Caderno CRH, v. 25, n. 65, p.187-210, 2012.

MANN, Michael. A crise do Estado-nação latino-americano. In: DOMINGUES, J. M.; MANEIRO, M. (Orgs.). América Latina hoje. Rio de Janeiro: Civilização Brasileira, 2006. p.165-193.

MARINI, Ruy. Dialéctica de la dependência. Cidade do México: Ediciones Era, 1977.

MARTIN-BARBERO, Jesús. Projetos de Modernidade na America Latina. In: DOMINGUES, J. M.; MANEIRO, M. (Orgs.). América Latina hoje. Rio de Janeiro: Civilização Brasileira, 2006, p. 19-51.

PREBISCH, Raúl. O desenvolvimento da América Latina e alguns de seus problemas principais. In: BIELSCHOWSKY, Ricardo. Cinquenta anos de pensamento na CEPAL. São Paulo: Record, 2000.

ROSTOW, Walt Whitman. The Stages of Economic Growth. The Economic History Review. Second Series, v. 13, n.1, p.1-16, 1959. 
184 | Isabela Veloso Lopes Versiani, Anete Marília Pereira e Maria da Luz Alves Ferreira

SANTOS, Theotonio. The structure of dependence. American Economic Review, v. 60, n. 2, p. 231$236,1970$.

Texto recebido em 15 de outubro de 2018. Aprovado em 16 de novembro de 2018. 